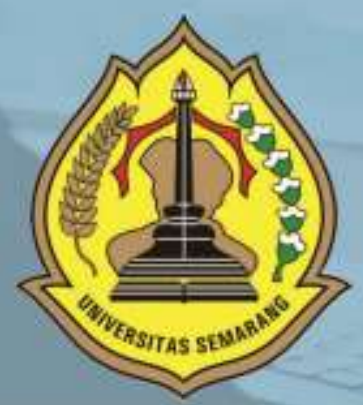

PENGARUH WORK FAMILY CONFLICT, STRES KERJA DAN KEPEMIMPINAN TERHADAP TURNOVER INTENTION KARYAWAN (STUDI PADA SELURUH KARYAWAN BAGIAN PLANNING PRODUCTION AND INVENTORY CONTROL PT. PARKLAND WORLD INDONESIA JEPARA

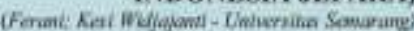

STUDI SOFT SKILL LULUSAN PENDIDIKAN KEJURUAN DI TEMPAT KERJA

Whort-Chiversikio Semorang

ANALISIS IINGKUNGAN INTERNAL DAN EKSTERNAL, PADA UKM PREMIUM PLUS LAUNDRY CABANG MULAWARMAN SEMARANG

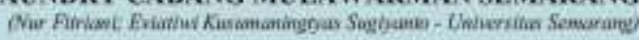

FAKTOR-FAKTOR YANG MEMPENGARUHI PERTIMBANGAN TINGKAT MATERIALITAS AUDIT

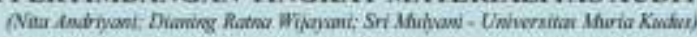

MANAJEMEN LABA DAN FAKTOR-FAKTOR YANG MEMPENGARUHINYA (STUDI EMPIRIS PADA PERUSAHAN MANUFAKTUR DI BEI)

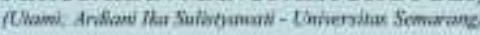

PENDAPATAN ASLI DAERAH, DANA PERIMBANGAN, DAN SISA LEBIH PEMBIAYAAN ANGGARAN TERHADAP PENGALOKASIAN BELANJA MODAL: STUDI PADA KABUPATEN/KOTA DI PROVINSI JAWA TENGAH

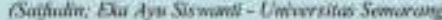

PERSEPSI PENGGUNA JASA TRANS JATENG TERHADAP KUALITAS PELAYANAN ANGKUTAN AGLOMERASI PERKOTAAN TRANS

JATENG

(Studi Kasus Trans Jateng Koridor I Semarang (Tawang) - Bawen)

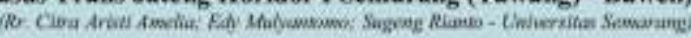

WORTHLESSNESS IS A POWER: MENGAPA ORANG BERSEDIA MENARUH UANG DI APLIKASI GO-PAY

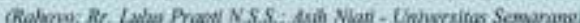

ANALISIS PENGARUH KUALITAS PRODUK, PERSEPSI HARGA, DAN PROMOSI TERHADAP KEPUTUSAN PEMBEIIAN WELLBLUE AL KALINE WATER PITCHER

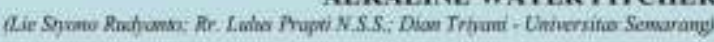

STRATEGI PEMASARAN UNTUK MENINGKATKAN VOLUME PENJUALAN (STUDI KASUS PADA SHOFA CATERING)

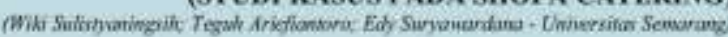

PENGARUH CITRA MEREK, PERSEPSI HARGA, DAN KUALITAS PRODUK TERHADAP KEPUTUSAN PEMBELIAN SEPATU OLAH RAGA MEREK ADIDAS

(Studi di Kota Semarang)

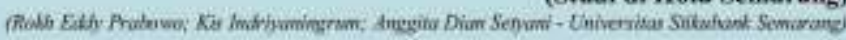

PENGARUH KEMUDAHAN TERHADAP KEPUTUSAN MENGGUNAKAN E-BANKING PADA BNI 46 KC KARANGAYU SEMARANG DENGAN MINAT NASABAH DAN KEPERCAYAAN SEBAGAI VARIABEL. MEDIASI

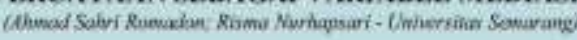

PENELITLAN KEBERLANGSUNGAN USAHA ARDANI INDONESIA SEBAGAI UMKM BERBASIS INDUSTRI KREATIF

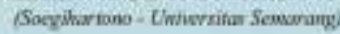

STRATEGI PELAYANAN BUS RAPID TRANSIT (BRT) TRANS SEMARANG

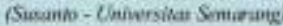

ANALISIS PENGARUH KEPEMIMPINAN, STRES KERJA, DAN LINGKUNGAN KERJA TERHADAP KINERJA KARYAWAN BAGIAN PRODUKSI SEWING PT. SAMWON BUSANA INDONESIA SEMARANG

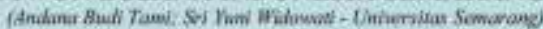




\section{DESKRIPSI}

Majalah IImiah Solusi Mengkaji

Masalah-Masalah Sosial,

Ekonomi dan Bisnis

\section{KETERANGAN TERBIT}

Terbit Pertama Kali Juli 2002

dan SelanjutnyaTerbit Tiga Bulan

Sekali (Januari, April, Juli dan

Oktober)

\section{PENERBIT}

Fakultas Ekonomi USM

\section{ALAMAT PENERBIT}

JL. Soekarno Hatta Semarang

Telp. 024-6702757 Fax. 024-6702272

\section{PENGELOLA}

Editor in Chief : Yohanes Suhardjo, SE, M.Si., Ak, CA Vice Editor Chief : Sugeng Rianto, SE, MM

Managing Editor: Edy Suryawardana, SE, MM

Secretary of Managing Editor : Asih Niati, SE, MM

Administration \& Circulation :

Citra Rizkiana, SE, MM

Layout \& Typesetting : M Burhan Hanif S.Kom, M.Kom

Board of Editors:

1. Prof. Dr. Ir. Kesi Widjajanti, SE, MM (USM)

2. Prof. Drs. Mohammad Nasir, Msi, Ph.D, AK. (USM)

3. Prof. Supramono SE, MBA, DBA (UKSW)

4. Prof. Drs. H. Imam Ghozali, M.Com, Akt, PhD (UNDIP)

5. Prof. Dr. Agus Suroso, MS (UNSOED)

6. Prof. Dr. Widodo, SE, M.Si (UNISSULA)

7. Prof. Dr. Dra. Sulastri, ME, M.Kom (UNSRI)

8. Dr. Ardiani Ika S, SE, MM, Ak, CA, CPA (USM)

\section{KATA PENGANTAR}

Sungguh merupakan kebahagiaan tersendiri bagi kami, takala kami dapat hadir rutin setiap tiga bulan sekali untuk saling bertukar pikiran mengenai hal-hal baru dibidang sosial, ekonomi dan bisnis.

Pada kesempatan ini penerbit menyampaikan terima kasih kepada semua pihak yang telah mengirimkan artikel-artikelnya. Penerbit akan membuka kesempatan seluas-luasnya bagi seluruh kalangan akademisi maupun praktisi baik dari dalam maupun luar Universitas Semarang untuk mempublikasikan karya ilmiahnya.

Penerbitan majalah ilmiah "SOLUSI" kali ini menghadirkan 15 (Lima Belas) artikel yang kami anggap layak untuk diterbitkan, dengan harapan dapat menjadi tambahan referensi bagi para pembaca dan menjadi sumbangan pengembangan persemaian khasanah pengetahuan dibidang sosial, ekonomi dan bisnis.

Akhir kata semoga majalah ilmiah "SOLUSI" dapat memberi manfaat yang sebesar-besarnya.

Hormat Kami 


\section{DAFTAR ISI}

PENGARUH WORK FAMILY CONFLICT, STRES KERJA DAN KEPEMIMPINAN TERHADAP TURNOVER INTENTION KARYAWAN (STUDI PADA SELURUH KARYAWAN BAGIAN PLANNING PRODUCTION AND INVENTORY CONTROL PT. PARKLAND WORLD INDONESIA JEPARA)

(Ferani; Kesi Widjajanti - Universitas Semarang)

STUDI SOFT SKILL LULUSAN PENDIDIKAN KEJURUAN DI TEMPAT KERJA

(Albert - Universitas Semarang)...

ANALISIS LINGKUNGAN INTERNAL DAN EKSTERNAL PADA UKM PREMIUM PLUS

LAUNDRY CABANG MULAWARMAN SEMARANG

(Nur Fitriani; Eviatiwi Kusumaningtyas Sugiyanto - Universitas Semarang)

FAKTOR-FAKTOR YANG MEMPENGARUHI PERTIMBANGAN TINGKAT

MATERIALITAS AUDIT

(Nita Andriyani; Dianing Ratna Wijayani; Sri Mulyani - Universitas Muria Kudus).

MANAJEMEN LABA DAN FAKTOR-FAKTOR YANG MEMPENGARUHINYA

(STUDI EMPIRIS PADA PERUSAHAN MANUFAKTUR DI BEI)

(Utami; Ardiani Ika Sulistyawati - Universitas Semarang)

PENDAPATAN ASLI DAERAH, DANA PERIMBANGAN, DAN SISA LEBIH PEMBIAYAAN ANGGARAN TERHADAP PENGALOKASIAN BELANJA MODAL: STUDI PADA

KABUPATEN/KOTA DI PROVINSI JAWA TENGAH

(Saifudin; Eka Ayu Siswanti - Universitas Semarang).

PERSEPSI PENGGUNA JASA TRANS JATENG TERHADAP KUALITAS PELAYANAN ANGKUTAN AGLOMERASI PERKOTAAN TRANS JATENG

(Studi Kasus Trans Jateng Koridor I Semarang (Tawang) - Bawen)

(Rr. Citra Aristi Amelia; Edy Mulyantomo; Sugeng Rianto - Universitas Semarang)

WORTHLESSNESS IS A POWER: MENGAPA ORANG BERSEDIA MENARUH UANG DI APLIKASI GO-PAY

(Rahoyo; Rr. Lulus Prapti N.S.S.; Asih Niati - Universitas Semarang).

ANALISIS PENGARUH KUALITAS PRODUK, PERSEPSI HARGA, DAN PROMOSI TERHADAP KEPUTUSAN PEMBELIAN WELLBLUE ALKALINE WATER PITCHER

STRATEGI PEMASARAN UNTUK MENINGKATKAN VOLUME PENJUALAN (STUDI KASUS PADA SHOFA CATERING)

(Wiki Sulistyaningsih; Teguh Ariefiantoro; Edy Suryawardana - Universitas Semarang)

PENGARUH CITRA MEREK, PERSEPSI HARGA, DAN KUALITAS PRODUK TERHADAP KEPUTUSAN PEMBELIAN SEPATU OLAH RAGA MEREK ADIDAS

(Studi di Kota Semarang)

(Rokh Eddy Prabowo; Kis Indriyaningrum; Anggita Dian Setyani - Universitas Stikubank Semarang) .121

PENGARUH KEMUDAHAN TERHADAP KEPUTUSAN MENGGUNAKAN E-BANKING PADA BNI 46 KC KARANGAYU SEMARANG DENGAN MINAT NASABAH DAN KEPERCAYAAN SEBAGAI VARIABEL MEDIASI

(Ahmad Sahri Romadon; Risma Nurhapsari - Universitas Semarang) 
PENELITIAN KEBERLANGSUNGAN USAHA ARDANI INDONESIA SEBAGAI UMKM BERBASIS INDUSTRI KREATIF

(Soegihartono - Universitas Semarang)

STRATEGI PELAYANAN BUS RAPID TRANSIT (BRT) TRANS SEMARANG

(Susanto - Universitas Semarang).....

ANALISIS PENGARUH KEPEMIMPINAN, STRES KERJA, DAN LINGKUNGAN KERJA TERHADAP KINERJA KARYAWAN BAGIAN PRODUKSI SEWING PT. SAMWON BUSANA INDONESIA SEMARANG

(Andana Budi Tami; Sri Yuni Widowati - Universitas Semarang). 


\title{
PENGARUH WORK FAMILY CONFLICT, STRES KERJA DAN KEPEMIMPINAN TERHADAP TURNOVER INTENTION KARYAWAN (STUDI PADA SELURUH KARYAWAN BAGIAN PLANNING PRODUCTION AND INVENTORY CONTROL PT. PARKLAND WORLD INDONESIA JEPARA)
}

\author{
Ferani ${ }^{1}$ \\ Kesi Widjajanti ${ }^{2}$ \\ Saputriferani@gmail.com ${ }^{1}$ \\ Fakultas Ekonomi Universitas Semarang
}

Diterima: Agustus 2020, Disetujui: September 2020, Dipublikasikan: Oktober 2020

\begin{abstract}
This research is motivated by the reduced number of employees experienced by the company PT. Parkland World Indonesia Jepara. The reduction in the number of employees is inseparable from Turnover Intention. The purpose of this study was to analyze the effect of Work Family Conflict (X1), Job Stress (X2), and Leadership (X3) on Employee Turnover Intention (Y).

The population in this study were all employees of the PPIC division at PT. Parkland World Indonesia Jepara, totaling 304 people. The research sample was 75 respondents. The sample of this research was taken by using the Slovin formula. This study uses multiple linear analysis tools with the help of the SPSS program.

The results of the analysis using the SPSS program show that: 1). Job satisfaction is proven to have a positive effect on turnover intention. 2). Job stress is proven to have a negative effect on turnover intention. 3). Leadership is proven to have a positive effect on turnover intention. Keywords: Work Family Conflict, Job Stress, Leadership, Turnover Intention.
\end{abstract}

\begin{abstract}
ABSTRAK
Penelitian ini dilatarbelakangi oleh berkurangnya jumlah karyawan yang dialami oleh perusahaan PT. Parkland World Indonesia Jepara. Berkurangnya jumlah karyawan tidak terlepas dari Turnover Intention. Tujuan penelitian ini untuk menganalisis pengaruh Work Family Conflict (X1), Stres Kerja (X2), dan Kepemimpinan (X3) terhadap Turnover Intention (Y) karyawan.

Populasi dalam penelitian ini adalah seluruh karyawan bagian PPIC di PT. Parkland World Indonesia Jepara yang berjumlah 304 orang. Sampel penelitian sebanyak 75 orang responden. Pengambilan sampel penelitian ini dengan rumus Slovin. Penelitian ini menggunakan alat analisis linier berganda dengan bantuan program SPSS.

Hasil analisis dengan menggunakan program SPSS menunjukan bahwa:1). Kepuasan kerja terbukti berpengaruh positif terhadap turnover intention. 2). Stres kerja terbukti berpengaruh negatif terhadap turnover intention. 3). Kepemimpinan terbukti berpengaruh posit if terhadap turnover intention.
\end{abstract}

Kata Kunci : Work Family Conflict, Stres Kerja, Kepemimpinan, Turnover Intention. 


\section{PENDAHULUAN}

\section{Latar Belakang}

Globalisasi sekarang agar mampu bertahan pada bisnisnya. Perusahaan yang mampu bertahan adalah perusahaan yang berhasil membangun keunggulan kompetitif dan memiliki kinerja yang baik. Demi meningkatkan kinerja dan memenangkan persaingan, perusahaan harus memiliki strategi yang baik dalam mengelola bisnisnya. Pengelolaan sumberdaya secara efektif dan efisien dapat membantu perusahaan dalam mencapai tujuan perusahaan. Sumber daya perusahaan yang perlu dikelola dengan baik salah satuny adalah sumberdaya manusia. Sumberdaya manusia senantiasa melekat pada setiap perusahaan sebagai faktor penentu keberadaan dan berperan dalam memberikan kontribusi kearah pencapaian tujuan perusahaan secara efektif dan efesien. Perusahaan membutuhkan sumberdaya manusia yang handal dan berkualitas sehingga perusahaan harus dapat mengelola dan memperhatikan sumberdaya manusia dengan sebaik mungkin (Ni Wayan, dkk 2016).

Saat ini tingginya tingkat turnover intention telah menjadi permasalahan yang serius bagi banyak perusahaan, bahkan beberapa perusahaan mengalami frustasi ketika mengetahui proses rekrutmen yang telah berhasil menjaring staf yang berkualitas pada akhirnya ternyata memilih pekerjaan di perusahaan lain. Terjadinya turnover diawali dengan timbulnya keinginan untuk berpindah pekerjaan (turnover intention) oleh karyawan. Keinginan tersebut muncul pada saatkaryawan masih bekerja pada perusahaan dan dipengaruhi oleh banyak faktor. PT. Parkland World Indonesia Jepara adalah salah satu pabrik perindustrian sepatu Adidas yang berdiri sejak Januari 2016 dan di resmikan pada 08 september 2016. PT. Parkland World Indonesia Jepara selama 2 tahun terakhir cukup tinggi dari jumlah karyawan sebanyak 304 karyawan,terdata angka turnover yaitu dari sejumlah 51 karyawan masuk dan 31 karyawan keluar pada tahun 2018, Sedangkan pada tahun 2019 sejumlah 90 karyawan masuk dan 39 karyawan keluar. Menunjukan bahwa dari tahun 2018 ke 2019 angka turnover di PT. Parkland World Indonesia Jepara mengalami kenaikan setiap tahun. Data tersebut menunjukan bahwa karyawan yang keluar tidak diimbangi dengan karyawan yang masuk. Jika hal ini tidak segera diatasi akan mengganggu aktifitas kerja khususnya untuk operasional perusahaan dan meningkatkan biaya yang lebih besar untuk selalu merekrut karyawan.

\section{LANDASAN TEORI}

\section{Sumber Daya Manusia}

Sumber daya manusia adalah kemampuan terpadu daya pikir dan daya fisik yang dimiliki individu.Sumber daya manusia merupakan asset terpenting perusahaan yang harus terus dibina dan diarahkan agar perusahaan dapat terus berkembang. Pada hakikatnya SDM berupa manusia merupakan salah satu faktor yang terpenting dalam suatu perusahaan selain faktor yang lain seperti modal. Oleh karena itu sumber daya 
manusia harus dikelola dengan baik untuk meningkatkan efisiensi dan efektifitas suatu perusahaan.

\section{Turnover Intention}

Keinginan (intention) adalah niat yang timbul pada individu untuk melakukan sesuatu. Sementara turnover adalah berhentinya seorang karyawan dari tempatnya bekerja secara sukarela atau pindah dari satu tempat ke tempat lain. Dengan demikian, turnover intention (intensi keluar) adalah kecenderungan atau niat karyawan untuk berhenti bekerja dari pekerjaannya, Zeffane (dalam Fuhasari, 2016:10).

\section{Work Family Conflict}

Menurut Greenhaus \& Beutell (dalam Widya, 2019:97)work family conflict didefinisikan sebagai "A type of inter-role conflict wherein some responsibilities from the work and family domains are not compatible and have a negative influence on an employee's work situation." Artinya work-family conflict merupakan bentuk konflik peran dimana tuntutan peran dari pekerjaan dan keluarga tidak dapat disejajarkan dan mempunyai dampak yang buruk terhadap situasi kerja karyawan. Menurut Kinicki and Kreitner (dalam Widya, 2019:97) konflik yang terjadi antara pekerjaan dan keluarga (work-family conflict) merupakan hal yang saling bergantungan. Ketergantungan yang terjadi dalam work family conflict akan mengakibatkan adanya 2 arah hubungan yang saling berbeda, yaitu:work to family conflict konflik yang terjadi pada saat masalah pekerjaan dikantor mempengaruhi atau mengganggu kehidupan keluarganya, sehingga menimbulkan masalah.

\section{Stress Kerja}

Menurut Handoko (1987:200) mengemukan bahwa stres kerja merupakan suatu keadaan atau kondisi ketegangan yang mempengaruhi emosi, proses berfikir dan kondisi seseorang. Dampak stres kerja menurut Handoko (1987:202) antara lain mengganggu pekerjaan, prestasi kerja karyawan menurun karena mengganggu pekerjaan, karyawan menjadi tidak mampu mengambil keputusan-keputusan, perilaku karyawan jadi tidak teratur. Dan akibat yang paling ekstrim adalah prestasi kerja menjadi nol, karyawan sakit atau tidak kuat bekerja lagi, karyawan merasa putus asa, karyawan mempengaruhi orang-orang lain agar bekerja mencapai tujuan dan sasaran. Manajemen mencakup kepemimpinan, tetapi juga mencakup fungsi-fungsi lain seperti perencanaan, pengorganisasian dan pengawasan, Handoko (1984:294-295).

\section{Kepemimpinan}

Kepemimpinan adalah bagian penting manajemen, tetapi tidak sama dengan manajemen. Kepemimpinan merupakan kemampuan yang dipunyai seseorang untukTurnover 


\section{Hipotesis penelitian:}

H1 : Work Family Conflict berpengaruh terhadap turnover intention

H2 : Stress Kerja berpengaruh terhadap turnover intention

H3 : Kepemimpinan berpengaruh terhadap turnover intention

\section{METODE PENELITIAN}

\section{Variabel Penelitian}

Variabel penelitian ini adalah:

1. Variabel Terikat (Dependent Variabel) adalah Turnover Intention (Y).

2. Variabel Bebas (Independent Variabel) adalah work family conflict (X1), stress kerja (X2), dan kepemimpinan (X3).

\section{Metode Pengumpulan Data}

Adapun metode pengumpulan data yang dilakukan dalam penelitian ini adalah : Metode Wawancara, Kuesioner (Angket) dan Kajian Pustaka.

\section{HASIL PENELITIAN \\ Deskripsi Obyek Penelitian}

Responden dalam penelitian ini adalah para karyawan bagian PPIC. Berdasarkan 75 responden yang bekerja pada bagian PPIC melalui daftar pernyataan didapat kondisi responden tentang jenis kelamin, usia dan pendidikan.

\section{Analisis Data}

\section{Uji Validitas}

Hasil uji validitas menunjukan bahwa semua indikator yang digunakan untuk mengukur variabel dalam penelitian ini mempunyai $r$ hitung lebih besar dari $r$ tabel dengan demikian semua indikator dinyatakan valid.

\section{Uji Reliabilitas}

Hasil uji reliabilitas menunjukan bahwa semua variabel mempunyai koefisien Alpha yang cukup besar yaitu lebih besar dari 0,60 dengan demikian semua indikator menunjukan reliabel. 


\section{Analisis Regresi Linier Berganda}

Analisis regresi liner berganda dilakukan terhadap model lebih dari satu variabel bebas, untuk diketahui pengaruhnya terhdap variabel ikat dan analisis regresi berganda digunakan untuk mengetahui hipotesis tentang pengaruh variabel independen terhadap variabel dependen. Hasil pengujian memberikan nilai kefiesien persamaan regresi sebagai berikut. Berdasarkan hasil uji regresi linier berganda sepertitabel di atas, diperolehhasil $(Y)=14.522-.012 X_{1}-0,088 X_{2}+0,130 X_{3}$

\section{Koefisien Determinasi}

Koefisien korelasi $\mathrm{R}$ sebesar 0.026 sama dengan 2.6\%.Angka tersebut mengandung arti bahwa besarnya pengaruh variable bebasyaitu Work Family Conflict (X1), Stress Kerja (X2) dan Kepemimpinan (X3) terhadap variable terikat yaitu turnover intention (Y) adalah sebesar $2.6 \%$.

\section{Pembahasan}

\section{Pengaruh Work Family Conflict Terhadap Turnover Intention}

Ho diterima dan Ha ditolak yang menyatakan bahwa tidak terdapat pengaruh antara work family conflict terhadap turnover intention pada PT. Parkland World Indonesia Jepara. Hal ini berarti ada atau tidak adanya konflik pada pekerjaan dan keluarga tidak mempengaruhi karyawan pada keinginan keluar dari pekerjaan (turnover intention).

\section{Pengaruh Stress Kerja Terhadap Turnover Intention}

Ho diterima dan Ha ditolak yang menyatakan bahwa tidak terdapat pengaruh antara stres kerja terhadap turnover intention pada PT. Parkland World Indonesia Jepara. Stres kerja merupakan hal yang sudah pasti di alami oleh setiap pekerja, namun banyak juga yang pandai menyikapi stress tersebut. Pada karyawan bagian PPIC, stress kerja bukanlah salah satu hal yang memicu adanya keinginan untuk keluar karena mereka merasadapat menangani stress kerja dengan sharing dan menghabiskan waktu bersama keluarga.

\section{Pengaruh Kepemimpinan Terhadap Turnover Intention}

Ho ditolak dan Ha diterima yang menyatakan bahwa ada pengaruh yang positif antara kepemimpinan terhadap turnover intention pada PT. Parkland World Indonesia Jepara. Hal ini berarti semakin baik kepemimpinan seorang pemimpin karyawan maka akan mengurangi turnover intention karyawan, sebaliknya semakin buruk kepemimpinan maka akan meningkatkan turnover intention karyawan. 


\section{KESIMPULAN DAN SARAN}

\section{Kesimpulan}

Berdasarkan penelitian dan pembahasan mengenai pengaruh work family conflict, stress kerja dan kepemimpinan terhadap turnover intention karyawan PT. Parkland World Indonesia Jepara, maka dapat diambil kesimpulan sebagai berikut:

1. Work family conflict berpengaruh negative terhadap turnover intention karyawan bagian PPIC PT. Parkland World Indonesia Jepara

2. Stres bahwa berpengaruh negative terhadap turnover intention karyawan bagian PPIC PT. Parkland World Indonesia Jepara.

3. Kepemimpinan berpengaruh positif terhadap turnover intention karyawan karyawan bagian PPIC PT. Parkland World Indonesia Jepara

\section{Saran}

Beberapa hal yang menjadi saran dari peneliti kepada pihak-pihak terkait yang dalam hal ini khususnya adalah karyawan PT. Parkland World Indonesia Jepara agar dapat lebih mengurangi intention turnover salah satunya yaitu memberikan izin atau waktu karyawan untuk bersama keluarganya ketika karyawan membutuhkan waktu tersebut. Selain itu juga untuk mengurangi stress kerja karyawan dengan menempatkan pekerja sesuai pada kapasitas dan keahlian karyawan. Selanjutnya, meningkatkan kepemimpinan yang lebih baik, yang bias melindungi dan menjadi teladan bagi pengikut atau orang yang dipimipinnya.

Bagi peneliti yang tertarik melakukan penelitian sejenis diharapkan untuk mengobservasi dan mengeksplor hasil ebih jauh mengenai permasalahanpermasalahan yang terdapat pada PT. Parkland World Indonesia Jepara. Hal ini dimaksudkan untuk mendukung keberhasilan penelitian.

\section{Daftar Pustaka}

Fuhasari, Lilla. (2016). "Pengaruh Komitmen Organisasi, dan Beban Kerja Terhadap Turnover Intention". Skripsi. Yogyakarta: Universitas Negeri Yogyakarta

Nurul, dkk.2018."Analisis Pengaruh Work Family Conflict dan Beban Kerja Terhadap Stres Kerja Dalam Mempengaruhi Turnover Intention (Studi Pada Karyawan PT. Bank Negara Indonesia (Persero), Tbk Wilayah Semarang)". Dalam Jurnal Administrasi Bisnis, Volume 7 No. 2:Universitas Diponegoro.

Ni Wayan, dkk. 2016. "Pengaruh Work Family Conflict Dan Stress Kerja Wanita". Dalam E-Jurnal Ekonomi dan Bisnis:Universitas Udayana.

I Gede, dkk. 2017. "Pengaruh Kepemimpinan Dan Kepuasan Kerja Terhadap Turnover Intention Serta Dampaknya Terhadap Kinerja Karyawan Pada 
PT. Agung Automall Kuta”. Dalam E-Jurnal Ekonomi dan Bisnis Hal 24412474: Universitas Udayana.

Winda, dkk. 2018. "Hubungan Stress Kerja Dengan Turnover Intention Pada Karyawan Perusahaan Pembiayaan PT. FIF Group". Dalam E-Jurnalof psychology, volume 1 No. 1: Universitas Islam Negeri Raden Intan Lampung.

Yola, dkk. 2019. "Apakah Work-Family Conflict Berdampak Pada Turnover Intention?: Studi Pada Karyawan Wanita". Dalam Business \& Applied Management, volume 12 No. 1 Hal 91-106: Universitas Katolik Indonesia Atma Jaya.

Wisantyo, Nurmalitasari Indah., Harries Madiistriyatno. 2015. "Pengaruh Stres Kerja Disiplin Dan Kepuasan Kerja terhadap Intensi Turnover: Studi pada Lembaga Pengelola Dana Bergulir Koperasi dan Usaha Mikro, Kecil dan Menengah". Dalam Jurnal MIX, Volume V No. 1

Desko, dkk. 2019. "Pengaruh Beban Kerja, Disiplin Kerja, Kepuasan Kerja Dan Komitmen Organisasi Terhadap Turnover Intention”. Dalam Jurnal Riset Bisnis dan Manajemen, volume 7 No. 4: Universitas Sam Ratulangi.

Afrilia, Lisa Dwi., Hamidah Nayati Utami. 2018. "Pengaruh Work-Family Conflict Terhadap Kepuasan Kerja Dan Kinerja: Studi pada Karyawan Wanita Rumah Sakit Permata Bunda Malang". Dalam Jurnal Administrasi Bisnis, Volume 55 No. 2 Malang: Universitas Brawijaya.

Handoko, Hani. 1987. Manajemen Personalia \& Sumber Daya Manusia. Yogyakarta: BPFE-UGM.

Udriyah, dkk. 2017. "Pengaruh Beban Kerja, Work-Family Conflict Dan Job Insecurity Terhadap Kepuasan Kerja Serta Dampaknya Terhadap Turnover Intention Di PT. Bina Busana Internusa Semarang”. Dalam Jurnal Administrasi Bisnis, volume 18 No. 3 Semarang: Politeknik Negeri Semarang.

Septiari, Ni Ketut., I Komang Ardana. 2016. "Pengaruh Job Insecurity Dan Stres Kerja Terhadap Turnover Intention Karyawan Pada Hotel Asana Agung Putra Bali”. Dalam E-Jurnal Manajemen Unud, Volume 5 No. 10 Bali: Universitas Udayana.

Paaisal, La Ode Rachmat, dkk.2018. "Pengaruh Gaya Kepemimpinan Dan Budaya Organisasi Terhadap Turnover Melalui Kepuasan Kerja Karyawan Pada PT. Muara Wisesa Samudra di Jakarta”. Dalam Jurnal Eksekutif, volume 15 No. 1 Jakarta: Universitas Pancasila.

Prabowo, Rudi. 2018."Pengaruh Kepemimpinan Dan Komitmen Organisasi Terhadap Turnover Intention (Studi Pada Jajaran Reserse Kriminal Polres Gunung 
kidul)". Jurnal Studi Keislaman Vol. 4 No. 2 Oktober 2018 Yogyakarta: Universitas Islam Indonesia Yogyakarta.

Muna, Nailil. 2016.’Pengaruh Work-Family Conflict, Stress Kerja PadaTurnover Intention Dengan Kompensasi Sebagai Variabel Moderating”. Skripsi. Semarang: Universitas Sultan Agung.

Lusi, Rumanti. 2018.’Pengaruh Kepuasan Kerja, Stress Kerja Dan Lingkungan kerja Terhadap Turnover Intention Karyawan (Studi Kasus pada Seluruh Karyawan Bagian Produksi CV. Saprotan Utama Mranggen Demak)”. Skripsi. Semarang: Universitas Semarang.

Sekaran, Uma. (2006). Research Methods for business Edisi I and 2. Jakarta: SalembaEmpat.

Sugiyono. 2015. "Metode Penelitian Bisnis (Pendekatan Kuantitatif, Kualitatif, dan R\&D)". Bandung: Alfabeta.

Syahronica, Gabriela, dkk. (2015). "Pengaruh Kepuasan Kerja dan Stres Kerja Terhadap Turnover Intention (Studi pada Karyawan Departemen Dunia Fantasi PT. Pembangunan Jaya Ancol, Tbk). Jurnal Administrasi Bisnis (JAB) Vol. 20 No. 1 Maret 2015. Universitas Brawijaya Malang.

Ghozali,Imam.(2011). Aplikasi Analisis Multivariate dengan Program SPSS. Edisi 5. Semarang: Badan Penerbit Universitas Diponegoro.

Mudrajat, Kuncoro. (2013). Metode Riset untuk Bisnis \& Ekonomi Edisi 4. Jakarta: Penerbit Erlangga.

Pambudi, Cahya. A. 2014. Pemimpin dan Kepemimpinan Kita. www.djkn.kemenkeu.go.id/artikel/baca/7018/Pe mimpin-dan-KepemimpinanKita.html (diakses tanggal 25 Oktober 2019). 